\title{
Evaluation of factors which determining survival of SARS- COV-2 infected patients in intensive care unit
}

\author{
๑Iİnşa Gül Ekiz İşcanlı, ĐBengü Şaylan \\ University of Health Sciences, Sultan 2. Abdülhamid Han Training and Research Hospital, Department of Pulmonology, Respiratory Intensive \\ Care Unit, İstanbul, Turkey
}

Cite this article as: Ekiz İșcanlı İG, Şaylan B. Evaluation of factors which determining survival of SARS-COV-2 infected patients in intensive care unit. Anatolian Curr Med J 2021; 3(1); 36-43.

\begin{abstract}
Background: The disease SARS-COV-2, which started in Wuhan city of China and caused pandemic, created an increasing number of intensive care needs due to its severe respiratory failure. The factors that determine the course of patients followed in intensive care are different. Therefore, our aim was to determine the factors that predict mortality and affect prognosis by evaluating the patients admitted to our intensive care unit.

Material and Method: This study is a single-center retrospective study involving 156 patients admitted to our intensive care unit, who was diagnosed with SARS-COV-2 between 20 March and 8 June 2020. The data including characteristics, symptoms and laboratory findings of the patients were recorded and their relationships to mortality were evaluated

Results: The mean age was $69 \pm 15$ years and $63 \%$ were male. The most common symptom was dyspnea $(69.9 \%)$ and fever (60.9\%), respectively. Comorbidity was present in $82 \%$ and the most common comorbidity was HT and DM, respectively. All patients were admitted to the intensive care unit with (due to) hypoxemic respiratory failure. 106 patients (68.8\%) were connected to mechanical ventilation, which was associated with mortality $(\mathrm{p}<0.0001)$. High flow oxygen therapy was delivered in 31 patients and was associated with survival $(\mathrm{p}<0.05)$. Tocilizumab, given in addition to the treatments increased the survival $(\mathrm{p}<0.05)$.

Conclusion: We saw in our study that many parameters will be effective in predicting survival. As the most determining factors, not being intubated during admission and/or follow-up was observed to be effective on survival and was found to be associated with mortality.
\end{abstract}

Keywords: SARS-COV-2, intensive care unit, mortality, intubation

\section{INTRODUCTION}

A world-wide epidemic is called a pandemic. The Spanish flu, which infects a large part of the world's population in 1918 and killed about 50 million people, is the most well known (1). Covid-19 infection, which started endemically in December 2019 and caused an epidemic in China, was declared as a pandemic by WHO since it was seen in many countries worldwide (2). On February 11, 2020, 2019-nCoV, which emerged in 2019, was officially named SARS-COV-2 based on phylogeny, taxonomy and established practice, and the disease caused by SARS-COV-2 was also called Covid-19 $(3,4)$. SARS-COV-2 infection, which causes pandemic worldwide, progresses with high spreading rate, increasing need for intensive care and high intensive care mortality rate (5). The disease from a beta coronavirus family is also other family members

such as MERS and SARS-COV, and their mortality is $9.6 \%$ and $34.4 \%$, respectively $(6,7)$. The intensive care hospitalization needs of the patients are between 5-20\%, and the case mortality rates due to SARS-COV-2 vary between $0-16 \%$ in the world (8). However, the mortality rate is predicted to be lower due to the low number of cases detected.

In Turkey, the first case was detected on 10 March. To date, 190, 165 patients have been diagnosed and the number of mortalities is 5001 (9).

The disease shows a clinical presentation, ranging from an asymptomatic curse-especially in patients with comorbidity (diabetes, hypertension, heart failure) and in elderly patients-to cases requiring intensive care unit follow-up $(10,11)$. 
What is known about the incidence of hospitalization in the intensive care unit of patients diagnosed to date and the clinical course of the disease and the factors affecting it are limited. This study aims to identify and compare epidemiological, demographic, clinical, laboratory markers and radiological features, as well as complications, treatment and outcomes of patients hospitalized in the intensive care unit due to SARS-COV-2. Potential risk factors and death related factors for severe Covid-19 were analyzed to provide scientific data to alleviate severity and reduce mortality.

\section{MATERIAL AND METHOD}

All authors research and declare that the rules of publication ethics are followed. The study was carried out with the permission of Research Ethics Committee Ümraniye Training and Research Hospital (Permission granted/CAAE number: 2020/28.04, Decision no: 132). All procedures were performed adhered to the ethical rules and the Helsinki Declaration of Principles.

\section{Study Design}

This study included all patients over the age of 18 who were admitted to the Intensive Care Unit of Sağlık Bilimleri University Sultan Abdülhamid Han Training and Research Hospital due to SARS COV 2 between 20 March and 8 June. 156 patients whom diagnosed with Covid-19 according to the $\mathrm{WHO}$ and Covid-19 guidebook of the ministry of health were included in the study.

\section{Data collection}

Case data includes demographic features, clinical features, laboratory results, radiological images, treatment options, and results. All patients included were clinically and/ or laboratory (viral RNA detected by real-time PCR in oronasopharyngeal swabs) diagnosed and hospitalized patients over 18 years old. Chest x-ray and/or thoracic CT scan was used to confirm the diagnosis of pneumonia. There are no exclusion criteria.

Patients who had no fever for at least 3 days and whose respiratory functions improved significantly were taken to the clinics after being followed up in the intensive care unit.

\section{Statistical Analysis}

Because of the suitability of the Central Limit Theorem, parametric tests were used without testing normality (12). Non-parametric test statistics were used in laboratory measurement values with high deviations from the mean. In the analysis of the data, while performing the statistic given in the scales, the mean and standard deviation, minimum and maximum values of the features; When defining categorical variables, frequency and percentage values were used. Student's t test/Mann-Whitney U statistic is given to compare laboratory measurement values survived and nonsurvived group averages. Chi-square/z test statistics were used to evaluate the relationship between categorical variables. Exposure ratio (odds ratio) of variables thought to be related to death status are given. The statistical significance level of the data was taken as $\mathrm{p}<0.05$. In the evaluation of the data, www.epicos.com New York software and MedCalc statistics package program were used. Data collection was approved by the local Ethics Committee (17104_oss). The study was carried out in accordance with the Ethical Principles of the Helsinki Declaration and the Good Clinical Practice (GCP) guidelines of the International Conference on Harmonization (ICH).

\section{RESULTS}

The average age of 156 patients hospitalized in the intensive care unit from 20 March 2020 until 8 June 2020 was $69.3 \pm 15.2$, of which $63.5 \%$ were male. Increasing age (OR:1.03; 95\% Cl: 1.006-1.05; $\mathrm{p}=0.01$ ) and dyspnea (OR: $2.3 ; 95 \% \mathrm{Cl}: 1.1-4.4 ; \mathrm{p}=0.02$ ) were found to have a significant univariate association. The characteristics of the patients are shown in Table 1.

The presence of comorbidities (82\%) was found to be significant as a bad prognostic factor. The most common of these were Hypertension (48.7\%), second place Diabetes Mellitus (34.6\%) and third place lung diseases (COPD, asthma, bronchiectasis) (32.1\%) respectively. The presence of chronic kidney disease (CKD) and arrhythmia has been associated with mortality $(\mathrm{p}<0.05)$.

From application complaints, dyspnea (69.9\%) was the most common symptom, correlation with cough and hemoptysis was found in mortality, and the mortality of patients admitted to the clinic with dyspnea was increased 2.3 times $(\mathrm{p}<0.05)$.

Widespread bilateral ground-glass opacity in chest tomography was $78 \%$ in total and was associated with mortality $(\mathrm{p}<0.05)$.

At the time of admission, a treatment protocol consisting of chloroquine (97\%), an antiviral (94.8\%), an antibiotic (99.4\%) and azithromycin (76.3\%) was applied. Tocilizumab was used in 27 patients (17.4\%) and found beneficial for survival $(\mathrm{p}<0.05)$. There was no significant difference in other supportive treatments.

The fact that patients admitted to our intensive care unit from a different center other than our hospital services was associated with mortality. The mortality rate of patients coming from our hospital clinics is 4.13 times less. Patients intubated at the time of admission to intensive care unit are statistically significant in relation to mortality $(\mathrm{p}<0.05)$. $61 \%$ of the non-intubated patients were intubated later. Survival was proportional and correlated with high flow oxygen therapy mortality $(\mathrm{p}<0.05)$. 
Table 1. Patient characteristics related to mortality

\begin{tabular}{|c|c|c|c|c|c|}
\hline $\mathrm{N}=156$ & & Total & Discharged $n=59$ & Died n=97 & \\
\hline Characteristic & & n (\%) & n (\%) & n (\%) & $\mathbf{p}$ \\
\hline \multirow{3}{*}{ Gender } & Female & $57(36.5)$ & $25(42.4)$ & $32(33)$ & $0.24^{*}$ \\
\hline & Male & $99(63.5)$ & $34(57.6)$ & $65(67)$ & \\
\hline & & $\overline{\mathbf{x}} \pm \mathrm{SD}$ & $\overline{\mathbf{x}} \pm \mathrm{SD}$ & $\overline{\mathbf{x}} \pm \mathrm{SD}$ & \\
\hline Age & & $69.3 \pm 15.2$ & $65.3 \pm 17.7$ & $71.6 \pm 13.3$ & \multirow{3}{*}{$0.01^{\star *}$} \\
\hline Median (25\%-75\%) & & $70(59-81)$ & $70(51-80)$ & $71(62.5-81)$ & \\
\hline Minimum-maximum & & $25-99$ & $25-94$ & $33-99$ & \\
\hline Fever & Positive & $95(60.9)$ & $35(59.3)$ & $60(61.9)$ & $0.75^{\star}$ \\
\hline Cough & Positive & $89(57.1)$ & $40(67.8)$ & $49(50.5)$ & $0.03^{*}$ \\
\hline Dyspnea & Positive & $109(69.9)$ & $35(59.3)$ & $74(76.3)$ & $0.02^{\star}$ \\
\hline Hemoptysis & Positive & $7(4.5)$ & - & $7(7.2)$ & $0.03^{*}$ \\
\hline Lost of taste/smell & Positive & $5(3.2)$ & $3(5.1)$ & $2(2.1)$ & $0.3^{*}$ \\
\hline Comorbidities & Positive & $128(82.1)$ & $43(72.9)$ & $85(87.6)$ & $0.02^{*}$ \\
\hline Lung disease & Positive & $50(32.1)$ & $15(25.4)$ & $35(36.1)$ & $0.17^{\star}$ \\
\hline Coronary arter disease & Positive & $37(23.7)$ & $13(22)$ & $24(24.7)$ & $0.7^{\star}$ \\
\hline Diabetes mellitus & Positive & $54(34.6)$ & $18(30.5)$ & $36(37.1)$ & $0.4^{*}$ \\
\hline Chronic heart failure & Positive & $37(23.7)$ & $11(18.6)$ & $26(26.8)$ & $0.24^{*}$ \\
\hline Chronic kidney disease & Positive & $20(12.8)$ & $3(5.1)$ & $17(17.5)$ & $0.02^{*}$ \\
\hline Cancer & Positive & $16(10.3)$ & $7(11.9)$ & $9(9.3)$ & $0.61^{*}$ \\
\hline Hypertension & Positive & $76(48.7)$ & $27(45.8)$ & $49(50.5)$ & $0.56^{*}$ \\
\hline Cerebrovascular disease & Positive & $36(23.1)$ & $12(20.3)$ & $24(24.7)$ & $0.53^{*}$ \\
\hline Arrythmia & Positive & $18(11.5)$ & $1(1.7)$ & $17(17.5)$ & $0.003^{\star}$ \\
\hline Pneumonia & Positive & $154(98.7)$ & $57(96.6)$ & $97(100)$ & 0.07 \\
\hline Chest computed tomography & Bilateral infiltrates & $118(78.1)$ & $39(68.4)$ & $79(84)$ & $0.04^{\star}$ \\
\hline Lymphopenia & Positive & $142(92.2)$ & $55(93.2)$ & $87(91.6)$ & $0.71^{\star}$ \\
\hline Non-invasive ventilation (NIV) & Positive & $38(24.4)$ & $14(23.7)$ & $24(24.7)$ & $0.89^{\star}$ \\
\hline \multicolumn{6}{|l|}{ High flow nasale canule } \\
\hline (HFNC) & Positive & $31(19.9)$ & $18(30.5)$ & $13(13.4)$ & $0.009^{*}$ \\
\hline \multicolumn{6}{|l|}{ Invasive mechanical ventilation } \\
\hline$(\mathrm{IMV})$ & Positive & $108(69.2)$ & $14(23.7)$ & $94(96.9)$ & $<0.0001^{\star}$ \\
\hline Tracheostomy & Positive & $5(3.2)$ & $4(6.8)$ & $1(1)$ & $0.04^{*}$ \\
\hline Bedridden patients & Positive & $24(15.7)$ & $9(15.3)$ & $15(16)$ & $0.91^{\star}$ \\
\hline \multirow{3}{*}{ Arrival unit } & Other ICU & $20(13.2)$ & $6(10.2)$ & $14(15.1)$ & $0.08^{*}$ \\
\hline & Emergancy & $54(35.5)$ & $16(27.1)$ & $38(40.9)$ & \\
\hline & Clinic & $78(51.3)$ & $37(62.7)$ & $41(44.1)$ & \\
\hline \multirow[t]{2}{*}{ ICU admission } & Intubated & $31(20.3)$ & $5(8.5)$ & $26(27.7)$ & $0.004^{*}$ \\
\hline & Non-intubated & $122(79.7)$ & $54(91.5)$ & $68(72.3)$ & \\
\hline \multirow[t]{5}{*}{ Intubation time (0.48) } & First 1 hour & $18(25)$ & $1(11.1)$ & $17(27)$ & $<0.001^{\star * *}$ \\
\hline & First 24 hour & $22(30.6)$ & $2(22.2)$ & $20(31.7)$ & $<0.0001^{* * *}$ \\
\hline & 24-48 hour & $9(12.5)$ & $2(22.2)$ & $7(11.1)$ & $0.02^{\star * *}$ \\
\hline & 48 hour- 6 day & $16(22.2)$ & $2(22.2)$ & $14(22.2)$ & $<0.0001^{\star * *}$ \\
\hline & 7 day and more & $7(9.7)$ & $2(22.2)$ & $5(7.9)$ & $0.11^{\star * *}$ \\
\hline \multirow[t]{4}{*}{ Blood group } & 0 & $33(29.5)$ & $17(35.4)$ & $16(25)$ & $0.44^{*}$ \\
\hline & A & $51(45.5)$ & $22(45.8)$ & $29(45.3)$ & \\
\hline & B & $15(13.4)$ & $4(8.3)$ & $11(17.2)$ & \\
\hline & $\mathrm{AB}$ & $13(11.6)$ & $5(10.4)$ & $8(12.5)$ & \\
\hline Blood culture & Positive & $34(32.7)$ & $17(40.5)$ & $17(27.4)$ & $0.16^{*}$ \\
\hline
\end{tabular}

Follow-up with invasive mechanical ventilation $(\mathrm{p}<0.0001)$ and intubation took our attention as a bad prognostic factor. Our patients who underwent tracheostomy due to prolonged intubation were 5 patient and 4 of our patients were discharged $(\mathrm{p}<0.05)$. The blood type of 112 patients was examined; Group A was the most common (45.5\%). However, mortality was not associated.

${ }^{\star}$ Significant at the level $\mathrm{p}<0.05$ ( ${ }^{\star}$ Student's $\mathrm{t} /{ }^{* \star}$ MannWhitney U) 
The effect of duration of hospitalization and total hospital stay on mortality is statistically significant $(\mathrm{p}<0.05)$. It was observed that the average length of stay in hospital was higher in the discharged patients. The mean values of the APACHE II score and SOFA score were significantly higher in predicting mortality $(\mathrm{p}<0.0001)$. It was found that the average APACHE II value was higher in deceased patient. It was observed that the mean arterial pressure (MAP) was lower and its effect on mortality is significant $(\mathrm{p}<0.05)$. When the difference between the averages of glucose, AST, total bilirubin (OR:2.94; 95\% Cl: 1.227.07; $\mathrm{p}=0.03$ ), Blood Urea Nitrogen (BUN) (OR:1.01; 95\% Cl: 1.002-1.02; $\mathrm{p}=0.01)$, lactate dehydrogenase $(\mathrm{LDH})$, troponin, D-dimer, C-reactive protein (CRP) factors according to mortality is evaluated statistically, a significant effect is observed $(\mathrm{p}<0.05)$.

When the difference between the averages of CRP/ALB (OR: 1.04; 95\% Cl: 1.02-1.28; $\mathrm{p}=0.02$ ) factor according to mortality is evaluated statistically, a significant effect is observed $(p<0.05)$. It was found that the average CRP/ALB ratio was higher in deceased patients. When the difference between the mean of the Sedimentation factor according to mortality is evaluated statistically, a significant effect is observed $(\mathrm{p}<0.05)$. When the difference between the average of $\mathrm{SaO}_{2}$ and $\mathrm{PaO}_{2} / \mathrm{FiO}_{2}$ factors according to mortality is statistically evaluated, a significant effect is observed $(\mathrm{p}<0.05)$. It was found that the average $\mathrm{SaO}_{2}$ value was lower in patients who died. When the difference between the mean of Lactate (OR:1.54; 95\% Cl: 1.09-2.19 $\mathrm{p}=0.01$ ) factor (which is taken from arterial blood gas) by mortality is statistically evaluated, a significant effect is observed $(p<0.05)$. It was found that the average Lactate level was higher in deceased patients (Table 2).

\section{DISCUSSION}

This study is based on comparing the epidemiological, demographic, clinical and treatment data of patients admitted to our intensive care unit for Covid-19 infection (survived vs dead) and to determine the effects of them to mortality.

Our study was compatible with other studies and the effect of age factor on mortality was found statistically significant $(\mathrm{p}<0.05)(13)$. In our study, male gender was more common in admission to intensive care, as men were caught with more Covid-19. However, its effect on mortality has not been associated with gender (14).

Half of the 370,000 confirmed Covid-19 cases that were symptomatic in the United States had cough symptoms (15). In our study cough (57\%) was common and was associated with survival. In the same study $29 \%$ dyspnea was observed, and in our study, because of the only intensive care patients were included, the most common symptom was dyspnea with $69.9 \%$, and just like hemoptysis (it was seen in 7 patients but all died) it was also associated with mortality $(\mathrm{p}<0.05)(15)$.

As seen in many studies, SOFA Score, D-dimer, CRP, median values were higher in patients who died than those who survived (16). APACHE II score was also a marker of mortality, but NLR and PLR rates were not significant in predicting mortality. In addition, the CRP/Albumin ratio is defined as a prognostic biomarker in many diseases (ICU acceptance in some studies) when exceeds a certain rate (17). This may be also one of the values to be used as a biomarker of mortality in SARS-COV-2.

\begin{tabular}{|c|c|c|c|c|c|}
\hline Hydroxychloroquine sulfate & Positive & $152(97.4)$ & $57(96.6)$ & $95(97.9)$ & \\
\hline Antibiotic & Positive & $155(99.4)$ & $58(98.3)$ & $97(100)$ & $0.2^{*}$ \\
\hline Azythromycin & Positive & $119(76.3)$ & $45(76.3)$ & $74(76.3)$ & \\
\hline Broad-spectrum antibiotics & Positive & $144(92.9)$ & $53(91.4)$ & $91(93.8)$ & $0.57^{\star}$ \\
\hline Antiviral & Positive & $147(94.8)$ & $56(94.9)$ & $91(94.8)$ & $0.97^{\star}$ \\
\hline Antifungal & Positive & $21(13.5)$ & $8(13.6)$ & $13(13.5)$ & \\
\hline Corticosteroid & Positive & $52(33.5)$ & $19(32.2)$ & $33(34.4)$ & $0.78^{\star}$ \\
\hline IV Immunoglobulin & Positive & $1(0.6)$ & - & $1(1)$ & $0.43^{*}$ \\
\hline Plasma & Positive & $28(18.2)$ & $15(25.4)$ & $13(13.7)$ & $0.07^{\star}$ \\
\hline IL-6 inhibitor (Tocilizumab) & Positive & $27(17.4)$ & $18(30.5)$ & $9(9.4)$ & $0.001^{*}$ \\
\hline \multirow[t]{2}{*}{ Low molecular weight heparin } & proflactic & $91(58.3)$ & $26(44.1)$ & $65(67)$ & $0.008^{\star}$ \\
\hline & treatment dosage & $58(37.2)$ & $31(52.5)$ & $27(27.8)$ & \\
\hline Colchicin & Positive & $13(8.3)$ & $8(13.6)$ & $5(5.2)$ & $0.06^{*}$ \\
\hline Hemodialysis & Positive & $21(13.5)$ & $4(6.8)$ & $17(17.5)$ & $0.06^{*}$ \\
\hline Vitamin C & Positive & $127(81.4)$ & $45(76.3)$ & $82(84.5)$ & $0.2^{\star}$ \\
\hline Cytokine filter & Positive & $14(9)$ & $8(13.6)$ & $6(6.2)$ & $0.12^{\star}$ \\
\hline
\end{tabular}




\begin{tabular}{|c|c|c|c|c|}
\hline$[\mathrm{N}=153]$ & Total & Discharged $(n=59)$ & Died (n=94) & p-value \\
\hline Variable & $\overline{\mathbf{x}} \pm \mathrm{SD}$ & $\overline{\mathbf{x}} \pm$ SD & $\overline{\mathbf{x}} \pm \mathrm{SD}$ & \\
\hline Symptom & $9.2 \pm 11.8$ & $10.4 \pm 1.5$ & $8.4 \pm 7.4$ & $0.3^{\star}$ \\
\hline Clinical hospitalization (day) & $7.2 \pm 5.9$ & $9 \pm 6.1$ & $4.8 \pm 5$ & $0.001^{*}$ \\
\hline ICU hospitalization (day) & $9.8 \pm 9.2$ & $11.5 \pm 11.4$ & $8.8 \pm 7.4$ & $0.08^{*}$ \\
\hline Total hospitalization (day) & $14.3 \pm 10.9$ & $20.1 \pm 12.4$ & $10.8 \pm 8.4$ & $<0.0001^{*}$ \\
\hline APACHE II & $25.48 \pm 8.3$ & $20.77 \pm 6.05$ & $28.35 \pm 8.25$ & $<0.0001^{\star}$ \\
\hline SOFA & $5.94 \pm 3.23$ & $4.05 \pm 2.11$ & $7.1 \pm 3.3$ & $<0.0001^{\star}$ \\
\hline Heart rate rhythm $/ \mathrm{min}$. & $101.01 \pm 23.56$ & $100.44 \pm 23.35$ & $101.01 \pm 23.81$ & $0.81^{*}$ \\
\hline MAP & $87.62 \pm 19.26$ & $92 \pm 19.48$ & $84.96 \pm 18.74$ & $0.03^{*}$ \\
\hline Respiratory rate & $30.84 \pm 10.6$ & $31.61 \pm 8.09$ & $30.38 \pm 11.8$ & $0.48^{*}$ \\
\hline Leukocyte count & $12.75 \pm 17.17$ & $11.13 \pm 6.78$ & $13.74 \pm 21.15$ & $0.36^{*}$ \\
\hline Neutrophil & $9.79 \pm 6.43$ & $9.18 \pm 5.75$ & $10.16 \pm 6.82$ & $0.37^{\star}$ \\
\hline Lymphocytes & $0.95 \pm 0.65$ & $0.97 \pm 0.5$ & $0.94 \pm 0.73$ & $0.8^{*}$ \\
\hline Neutrophil/lymphocyte & $15.24 \pm 17.85$ & $13.7 \pm 17.55$ & $16.19 \pm 18.06$ & $0.4^{*}$ \\
\hline Hemoglobulin & $12.1 \pm 10.17$ & $11.28 \pm 2.75$ & $12.59 \pm 12.7$ & $0.44^{*}$ \\
\hline Hematocrit & $34.57 \pm 6.63$ & $34.67 \pm 7.57$ & $34.51 \pm 6.03$ & $0.88^{\star}$ \\
\hline Platelet & $230.64 \pm 109.25$ & $239.87 \pm 101.62$ & $224.96 \pm 113.83$ & $0.41^{*}$ \\
\hline Platelet/lymphocytes & $353.01 \pm 383.42$ & $333.18 \pm 357.91$ & $365.32 \pm 398.25$ & $0.61^{\star}$ \\
\hline Glucose & $154.19 \pm 99.93$ & $128.36 \pm 55.1$ & $169.79 \pm 116.64$ & $0.01^{*}$ \\
\hline ALT & $78.27 \pm 278.76$ & $44.72 \pm 53.41$ & $98.88 \pm 350.85$ & $0.15^{\star \star}$ \\
\hline AST & $98.1 \pm 349.05$ & $40.69 \pm 43.71$ & $133.38 \pm 439.358$ & $0.003^{\star *}$ \\
\hline Total bilurubin & $0.88 \pm 1.17$ & $0.64 \pm 0.3$ & $1.05 \pm 1.4$ & $0.03^{\star}$ \\
\hline Direct bilurubin & $0.47 \pm 1.01$ & $0.27 \pm 0.16$ & $0.6 \pm 1.27$ & $0.05^{*}$ \\
\hline BUN & $66.46 \pm 51.21$ & $53.37 \pm 48.75$ & $74.51 \pm 51.27$ & $0.01^{*}$ \\
\hline Creatine & $1.78 \pm 1.67$ & $1.56 \pm 1.58$ & $1.92 \pm 1.72$ & $0.2^{\star}$ \\
\hline $\mathrm{LDH}$ & $775.27 \pm 570.75$ & $614.22 \pm 317.22$ & $874.25 \pm 663.79$ & $0.006^{*}$ \\
\hline Troponin & $1314.79 \pm 5621.78$ & $501.9 \pm 3049.53$ & $1818.44 \pm 6708.75$ & $<0.0001^{* *}$ \\
\hline BNP & $772.25 \pm 1783.16$ & $546.33 \pm 706.29$ & $905.15 \pm 2179.33$ & $0.89^{* *}$ \\
\hline D-DIMER & $3339.38 \pm 5258.96$ & $2319.5 \pm 4418.56$ & $3996.64 \pm 5662.29$ & $0.01^{\star *}$ \\
\hline PT & $15.76 \pm 4.11$ & $15.21 \pm 3.29$ & $16.1 \pm 4.53$ & $0.19^{*}$ \\
\hline INR & $1.33 \pm 0.43$ & $1.28 \pm 0.34$ & $1.36 \pm 0.48$ & $0.24^{*}$ \\
\hline Fibrinogen & $597.09 \pm 209.54$ & $604.23 \pm 238.82$ & $592.76 \pm 191.22$ & $0.77^{\star}$ \\
\hline Ferritin & $1415.1 \pm 3048.28$ & $1024.16 \pm 2733.02$ & $1683.31 \pm 3235.13$ & $0.19^{* *}$ \\
\hline Prealbumin & $11.41 \pm 9.71$ & $13.21 \pm 9.42$ & $10.47 \pm 9.86$ & $0.32^{*}$ \\
\hline Albumin & $3.05 \pm 2.11$ & $3 \pm 0.48$ & $3.08 \pm 2.67$ & $0.81^{*}$ \\
\hline CRP & $13.83 \pm 16.34$ & $10.48 \pm 7.31$ & $15.94 \pm 19.78$ & $0.04^{*}$ \\
\hline CRP/ALB & $4.52 \pm 3.51$ & $3.66 \pm 2.97$ & $5.07 \pm 3.72$ & $0.02^{*}$ \\
\hline Procalcitonin & $3.51 \pm 10.23$ & $2.69 \pm 9.33$ & $4.04 \pm 10.7$ & $0.44^{*}$ \\
\hline Sedimentation & $69.25 \pm 34.05$ & $76.8 \pm 35.32$ & $64.27 \pm 32.44$ & $0.03^{*}$ \\
\hline Sodium & $137.38 \pm 6.17$ & $137.84 \pm 5.05$ & $137.11 \pm 6.77$ & $0.48^{*}$ \\
\hline Potassium & $4.2 \pm 0.75$ & $4.1 \pm 0.61$ & $4.25 \pm 0.82$ & $0.22^{*}$ \\
\hline $\mathrm{SaO}_{2}$ & $86.2 \pm 10.5$ & $88.87 \pm 9.18$ & $84.68 \pm 10.94$ & $0.02^{*}$ \\
\hline $\mathrm{PaO}_{2}$ & $66.59 \pm 29.94$ & $69.69 \pm 30.24$ & $64.8 \pm 29.79$ & $0.34^{*}$ \\
\hline $\mathrm{SaO}_{2} / \mathrm{PaO}_{2}$ & $4.07 \pm 19.32$ & $1.38 \pm 0.34$ & $5.65 \pm 24.24$ & $0.33^{\star *}$ \\
\hline $\mathrm{PaO}_{2} / \mathrm{FiO}_{2}$ & $128.79 \pm 59.61$ & $158.41 \pm 61.18$ & $111.45 \pm 51.55$ & $<0.0001^{*}$ \\
\hline Lactate & $2.53 \pm 2.58$ & $1.83 \pm 0.97$ & $2.92 \pm 3.09$ & $0.01^{\star}$ \\
\hline
\end{tabular}

The SARS-COV-2 virus is an enveloped, single chain virus, and the angiotensin converting enzyme 2 (ACE2) Receptor is thought to be a major receptor for the viral spike protein and is critical for infectivity. Considering that ACE2 protein is found at high levels in the biliary system and liver, it suggests tissue injury (18). Available data on Covid-19 showed that the incidence of abnormal ALT/AST ranges from $14 \%$ to $53 \%$ (19). In our study, similarly to recent studies, AST values were higher than ALT values and AST was associated with mortality $(p<0.05)$. In a study, the results of 6 studies in which bilirubin levels were measured were examined, and the results were found significantly higher in severe Covid-19 patients. In our study, total bilirubin and direct bilirubin levels were found associated with mortality significantly $(\mathrm{p}<0.05)(20,21)$.

Compared to patients in the surviving group, it is known that more frequent and more severe heart damage is observed in patients in the deceased group. One of the best indicator of this is that the high value of cardiac troponin I which is releated with cardiac damage caused by severe hypoxemia. In our study, cardiac troponin 
I value was found to be associated with mortality (22). Therefore, it may be valuable to save time for repairing cardiac damage by providing the oxygenation necessary to damage reduce cardiac. It was determined that the high duration of hospitalization in the intensive care unit and clinic was associated with survival. This situation indicates the necessity of a strategy for the protection of vital organs of patients in intensive care unit.

In our study, HFNC use was $19.9 \%$ and NIV use was $24.4 \%$. In other studies, HFNC use was $14-63 \%$ and NIV use was $11-56 \%(23-26)$. NIV use was not associated with survival or mortality, and HFNC use was associated with survival $(\mathrm{p}<0.05)$. A high mortality rate was encountered in patients intubated in our ICU. When we classified our patients who were followed up as non-intubated according to the time of intubation, the intubations performed within the first 7 days were found to be associated with mortality regardless of the intubation time. However, intubations performed after 7 days were not associated with mortality $(\mathrm{p}<0.05)$. Using other noninvasive respiratory supports without intubation may reduce mortality $(10,23,27)$.

In addition, the lactate value of patients with SARS-COV-2 examined during the application to the emergency room was used as a criterion for acceptance from emergency to intensive care; in our study, lactate level at the time of admission to intensive care unit was found to be related to mortality (28).

A blood groups causes coagulapathy and has been associated with mortality (29). However, in our patient group, although most patients were A blood groups, this was not associated with mortality. Unfortunately, there is no treatment for Covid-19 pneumonia that has been appointed and proven to be effective. For this reason, all our patients received combined therapy consisting of hydroxychloroquine, at least one antiviral therapy (famipravir, oseltamivir, ritonavir liponavir), vitamin C and antibiotic therapy. In our study, no drug affecting survival was found among them. Cytokinestorms mediated by overproduction of proinflammatory cytokines have been observed in a large population of critical patients infected with Covid-19 (20). In addition, combined therapies including steroids, colchicine, inhibition of IL-6, immunoglobulins and plasma therapy were also applied. Cytokine release syndrome is a systemic inflammatory response that is characterized by an increase in the level of a large number of pro-inflammatory cytokines and can develop for several reasons $(30,31)$. In a study conducted in Italy, 179 of 544 severe covid patients were treated with tocilizumab, and mortality was reduced in these patients (32). In our study, only tocilizumab was determinant in mortality and influenced survival (22).
Table 4. Evaluation of factors affecting mortality

\begin{tabular}{|c|c|c|c|c|}
\hline Variable & $\begin{array}{l}\text { Odds } \\
\text { ratio }\end{array}$ & $\begin{array}{c}\text { Lower } \\
(95 \% \text { CI })\end{array}$ & $\begin{array}{c}\text { Upper } \\
(95 \% \text { CI })\end{array}$ & $p$ value \\
\hline Age & 1.03 & 1.006 & 1.05 & $(\mathrm{p}<0.05)$ \\
\hline Gender (female) & 1.49 & 0.77 & 2.91 & $(p>0.05)$ \\
\hline $\begin{array}{l}\text { Duration of } \\
\text { symptom }\end{array}$ & 0.98 & 0.95 & 1.02 & $(p>0.05)$ \\
\hline Fever & 1.11 & 0.57 & 2.15 & $(\mathrm{p}>0.05)$ \\
\hline Cough & 0.48 & 0.25 & 1.0001 & $(p>0.05)$ \\
\hline Dispne & 2.3 & 1.1 & 4.4 & $(\mathrm{p}<0.05)$ \\
\hline Hemoptysis & 4.51 & 0.54 & 37.62 & $(p>0.05)$ \\
\hline Loss of taste/smell & 0.39 & 0.06 & 2.42 & $(p>0.05)$ \\
\hline Contact & 1.09 & 0.53 & 2.25 & $(p>0.05)$ \\
\hline $\begin{array}{l}\text { Admitted from } \\
\text { clinic }\end{array}$ & 4.13 & 1.49 & 11.47 & $(\mathrm{p}<0.05)$ \\
\hline $\begin{array}{l}\text { Heart rate rhythm/ } \\
\text { min. }\end{array}$ & 1.002 & 0.98 & 1.01 & $(p>0.05)$ \\
\hline MAP & 0.98 & 0.96 & 1.001 & $(p>0.05)$ \\
\hline Respiratory rate & 0.98 & 0.96 & 1.02 & $(p>0.05)$ \\
\hline Fever & 1.46 & 0.74 & 2.92 & $(p>0.05)$ \\
\hline Leukocyte count & 1.01 & 0.98 & 1.05 & $(p>0.05)$ \\
\hline Lymphopenia & 0.79 & 0.23 & 2.75 & $(p>0.05)$ \\
\hline $\begin{array}{l}\text { Neutrophil/ } \\
\text { lymphocyte }\end{array}$ & 1.009 & 0.99 & 1.03 & $(p>0.05)$ \\
\hline Hemoglobulin & 1.02 & 0.95 & 1.1 & $(p>0.05)$ \\
\hline Hematocrit & 0.99 & 0.95 & 1.05 & $(p>0.05)$ \\
\hline $\begin{array}{l}\text { Platelet/ } \\
\text { lymphocytes }\end{array}$ & 0.98 & 0.97 & 1.001 & $(\mathrm{p}>0.05)$ \\
\hline Glucose & 1.005 & 1.001 & 1.01 & $(\mathrm{p}<0.05)$ \\
\hline ALT & 1.003 & 0.99 & 1.007 & $(p>0.05)$ \\
\hline AST & 1.007 & 0.99 & 1.01 & $(p>0.05)$ \\
\hline Total bilurubin & 2.94 & 1.22 & 7.07 & $(\mathrm{p}<0.05)$ \\
\hline BUN & 1.01 & 1.002 & 1.02 & $(\mathrm{p}<0.05)$ \\
\hline Creatine & 1.16 & 0.92 & 1.45 & $(p>0.05)$ \\
\hline LDH & 1.001 & 0.99 & 1.002 & $(p>0.05)$ \\
\hline Troponin & 0.98 & 0.96 & 1.001 & $(p>0.05)$ \\
\hline BNP & 0.99 & 0.98 & 1.001 & $(p>0.05)$ \\
\hline D-dimer & 0.97 & 0.96 & 1.0001 & $(p>0.05)$ \\
\hline PT & 1.06 & 0.97 & 1.17 & $(p>0.05)$ \\
\hline INR & 1.69 & 0.69 & 4.16 & $(p>0.05)$ \\
\hline Fibrinogen & 0.99 & 0.98 & 1.001 & $(p>0.05)$ \\
\hline Ferritin & 0.96 & 0.95 & 1.001 & $(p>0.05)$ \\
\hline CRP/ALB & 1.14 & 1.02 & 1.28 & $(\mathrm{p}<0.05)$ \\
\hline Sedimentation & 0.98 & 0.97 & 1.001 & $(p>0.05)$ \\
\hline $\mathrm{SaO}_{2} / \mathrm{PaO}_{2}$ & 1.52 & 0.61 & 3.75 & $(p>0.05)$ \\
\hline $\mathrm{PaO}_{2} / \mathrm{FiO}_{2}$ & 0.98 & 0.97 & 1.0001 & $(p>0.05)$ \\
\hline Lactate & 1.54 & 1.09 & 2.19 & $(\mathrm{p}<0.05)$ \\
\hline
\end{tabular}


In our intensive care unit, our mortality was $62.5 \%$, but in many studies, mortality rates varies $26 \%$ to $78 \%(10,20,23,24,33)$. Here, treatment protocols, age, comorbidity, severity of disease and severity of acute respiratory distress syndrome (ARDS), differences between hospitals, may have caused different mortality rates.

\section{CONCLUSION}

With this study, we tried to find the factors predicting and affecting mortality. Thus, we aimed to identify patients who need careful observation and early intervention and to direct the clinician. Dyspnea was the most common symptom in admission to the intensive care unit, and was associated with mortality. We found that intubation is associated with mortality and using HFNC may reduce mortality. It was found useful to try non-invasive respiratory supports before intubation in the intensive care unit. Biochemical data (especially total bilirubin, direct bilirubin, glucose, BUN, lactate measured in arterial blood) obtained in admission to the intensive care unit were found to be helpful in predicting mortality.

\section{ETHICAL DECLARATIONS}

Ethics Committee Approval: The study was carried out with the permission of Research Ethics Committee Ümraniye Training and Research Hospital (Permission granted/CAAE number: 2020/28.04, Decision no: 132).

Informed Consent: Because the study was designed retrospectively, no written informed consent form was obtained from patients.

Referee Evaluation Process: Externally peer-reviewed.

Conflict of Interest Statement: The authors have no conflicts of interest to declare.

Financial Disclosure: The authors declared that this study has received no financial support. Author Contributions: All of the authors declare that they have all participated in the design, execution, and analysis of the paper, and that they have approved the final version.

\section{REFERENCES}

1. Grennan D. What is a pandemic? JAMA 2019; 321: 910. doi: 10.1001/jama.2019.0700.

2. World Health Organization. General's opening remarks at the media briefing on Covid-19. 2020. Available at: https://www. who.int/director-general/speeches/detail/who-director-generals-opening-remarks-at-the-media-briefing-on-covid-19---11march-2020

3. Coronaviridae Study Group of the International Committee on Taxonomy of Viruses. The species Severe acute respiratory syndrome-related coronavirus: classifying 2019-nCoV and naming it SARS-COV-2 [J]. Nat Microbiol 2020; 5: 536-44.
4. World Health Organization. WHO Director-General's remarks at the media briefing on 2019-nCoV on 11 February 2020. Available at: $\quad$ https://www.who.int/dg/speeches/detail/whodirectorgeneral-s-remarks-at-the-media-briefing-on

5. World Health Organization. Coronavirus disease 2019 (Covid-19) Situation Report-51 https://www.who.int/docs/default-source/ coronaviruse/situation-reports/20200311-sitrep-51-covid-19. pdf?sfvrsn=1ba62e57_10 (Accessed on 06 June, 2020)

6. Middle East Respiratory Syndrome Coronavirus. Available at: https://www.who.int/emergencies/mers-cov/en/. Accessed 06 June 2020

7. World Health Organization. Summary of probable SARS cases with onset of illness from 1 November 2002 to 31 July 2003.] Availablefromhttps://www.who.int/csr/sars/country/ table2004_04_21/en/

8. Johns Hopkins University the Center for Systems Science and Engineering (JHU-CSSE) Coronavirus Resource Center https:// coronavirus.jhu.edu/data/mortality Accessed 06 June 2020.

9. The Republic of Turkey Ministry of Health General Directorate of Public Health. Accessed 24 JUNE 2020. Available from:https:// hsgm.saglik.gov.tr/tr/covid19

10. Wang $\mathrm{D}, \mathrm{Hu} \mathrm{B}, \mathrm{Hu} \mathrm{C}$, et al. Clinical characteristics of 138 hospitalized patients with 2019 novel coronavirus-infected pneumonia in Wuhan, China. JAMA 2020; 323: 1061-9. doi:10.1001/jama.2020.1585

11. Guan WJ, Ni ZY, Hu Y, et al. Clinical characteristics of coronavirus disease 2019 in China. N Engl J Med 2020; 382: 1708-20. doi:10.1056/NEJMoa2002032

12. Norman G. Likert scales, levels of measurement and the "laws" of statistics. Adv Health Sci Educ Theory Pract 2010; 15: 625-32.

13. Wu Z, McGoogan JM. Characteristics of and important lessons from the coronavirus disease 2019 (Covid-19) outbreak in China: summary of a report of 72314 cases from the Chinese Center for Disease Control and Prevention. JAMA 2020; 323: 1239-42.

14. Ruan Q, Yang K, Wang W, Jiang L, Song J. Clinical predictors of mortality due to Covid-19 based on an analysis of data of 150 patients from Wuhan, China. Intensive Care Med 2020; 46: 8468. doi: 10.1007/s00134-020-05991-x

15. Stokes EK, Zambrano LD, Anderson KN, et al. Coronavirus disease 2019 case surveillance - United States, January 22-May 30, 2020. MMWR Morb Mortal Wkly Rep. 2020; 69: 759-65. doi:10.15585/mmwr.mm6924e2.

16. Auld S, Caridi-Scheible M, Blum JM, et al. ICU and ventilator mortality among critically ill adults with Covid-19. Preprint. medRxiv 2020; 2020.04.23.20076737. doi:10.1101/2020.04.23.20076737

17. Yu ST, Zhou Z, Cai Q, et al. Prognostic value of the C-reactive protein/albumin ratio in patients with laryngeal squamous cell carcinoma. Onco Targets Ther 2017; 10: 879-84.

18. Chai $\mathrm{X}, \mathrm{Hu} \mathrm{L}$, Zhang $\mathrm{Y}$, et al. Specific ACE2 expression in cholangiocytes may cause liver damage after 2019-nCoV infection. bioRxiv. 2020. doi.org/10.1101/2020.02.03.931766

19. Zhang C, Shi L, Wang FS. Liver injury in Covid-19: management and challenges. Lancet Gastroenterol Hepatol 2020; 5: 428-30.

20. Huang C, Wang Y, Li X, et al. Clinical features of patients infected with 2019 novel coronavirus in Wuhan, China. Lancet 2020; 395: 497-506.

21. Paliogiannis P, Zinellu A. Bilirubin levels in patients with mild and severe Covid-19: A pooled analysis. Liver Int 2020; 40: 17878. doi:10.1111/liv.14477.

22. Du RH, Liang LR, Yang CQ, et al. Predictors of mortality for patients with Covid-19 pneumonia caused by SARS-CoV-2: a prospective cohort study. Eur Respir J 2020; 55: 2000524. doi:10.1183/13993003.00524-2020. 
23. Grasselli G, Zangrillo A, Zanella A, et al. Baseline Characteristics and Outcomes of 1591 Patients Infected With SARS-COV-2 Admitted to ICUs of the Lombardy Region, Italy. JAMA 2020; 323: 1574-81.

24. Yang X, Yu Y, Xu J, et al. Clinical course and outcomes of critically ill patients with SARS-COV-2 pneumonia in Wuhan, China: a single-centered, retrospective, observational study. Lancet Respir Med 2020; S2213-2600(20)30079-5. doi:10.1016/S22132600(20)30079-5

25. Wu C, Chen X, Cai Y, et al. Risk Factors Associated With Acute Respiratory Distress Syndrome and Death in Patients With Coronavirus Disease 2019 Pneumonia in Wuhan, China. JAMA Intern Med 2020; 180: 934-43. doi:10.1001/ jamainternmed.2020.0994.

26. Myers LC, Parodi SM, Escobar GJ, Liu VX. Characteristics of hospitalized adults with Covid-19. JAMA 2020; 323: 2195-8.

27. Arentz M, Yim E, Klaff L, et al. Characteristics and outcomes of 21 critically ill patients with Covid-19 in Washington State. JAMA 2020; 323: 1612-4. doi:10.1001/jama.2020.4326

28. Carlino MV, Valenti N, Cesaro F, et al. Predictors of intensive care unit admission in patients with coronavirus disease 2019 (Covid-19). Monaldi Arch Chest Dis 2020; 90. doi:10.4081/ monaldi.2020.1410

29. Bernd Sebastian Kamps, Christian Hofmann COVID reference. 2020; 4: 215.

30. Shimabukuro-Vornhagen A, Gödel P, Subklewe M, et al. Cytokine release syndrome. J Immunother Cancer 2018; 6: 56.

31. Teijaro JR. Cytokine storms in infectious diseases. Semin Immunopathol 2017; 39: 501-3. doi:10.1007/s00281-017-0640-2

32. Guaraldi G, Meschiari M, Cozzi-Lepri A, et al. Tocilizumab in patients with severe Covid-19: a retrospective cohort study. Lancet Rheumatol 2020; 2: 474-84. doi:10.1016/S2665-9913(20)30173-9.

33. Richardson S, Hirsch JS, Narasimhan M, et al. Presenting characteristics, comorbidities, and outcomes among 5700 patients hospitalized with Covid-19 in the New York City Area. JAMA 2020; 323: 2052-9. doi:10.1001/jama.2020.6775. 